\title{
COMORBIDITIES IN SEVERE ASTHMA: FREQUENCY OF RHINITIS, NASAL POLYPOSIS, GASTROESOPHAGEAL REFLUX DISEASE, VOCAL CORD DYSFUNCTION AND BRONCHIECTASIS
}

\author{
Carla Bisaccioni, Marcelo Vivolo Aun, Edcarlos Cajuela, Jorge Kalil, Rosana \\ Câmara Agondi, Pedro Giavina-Bianchi
}

doi: $10.1590 / \mathbf{S 1 8 0 7 - 5 9 3 2 2 0 0 9 0 0 0 8 0 0 0 1 0}$

\begin{abstract}
Bisaccioni C, Aun MV, Cajuela E, Kalil J, Agondi RC, Giavina-Bianchi P. Comorbidities in severe asthma: frequency of rhinitis, nasal polyposis, gastroesophageal reflux disease, vocal cord dysfunction and bronchiectasis. Clinics. 2009;64(8):769-73.

OBJECTIVES: Severe asthma is found in approximately $10 \%$ of patients with asthma. Some factors associated with worse asthma control include rhinitis, gastroesophageal reflux disease, vocal cord dysfunction (VCD), nasal polyposis and bronchiectasis. Therefore, we evaluated the prevalence of these illnesses in patients with severe asthma.

METHODS: We conducted a retrospective analysis of data obtained from electronic medical records of patients with severe asthma between January 2006 and June 2008. Symptoms of rhinitis and gastroesophageal reflux disease were evaluated as well as intolerance to nonsteroidal anti-inflammatory drugs. We evaluated the results of esophagogastroduodenoscopy, videolaryngoscopy and CT scans of the chest in order to confirm gastroesophageal reflux disease, nasal polyposis, vocal cord dysfunction and bronchiectasis. RESULTS: We evaluated 245 patients. Rhinitis symptoms were present in 224 patients (91.4\%); 18 (7.3\%) had intolerance to nonsteroidal anti-inflammatory drugs, and $8(3.3 \%)$ had nasal polyposis. Symptoms of gastroesophageal reflux disease were reported for $173(70.6 \%)$ patients, although the diagnosis of gastroesophageal reflux disease was confirmed based on esophagogastroduodenoscopy or laryngoscopy findings in just $58(33.6 \%)$ patients. Vocal cord dysfunction was suspected in $16(6.5 \%)$ and confirmed through laryngoscopy in 4 (1.6\%). The patient records provided CT scans of the chest for 105 patients, and 26 (24.8\%) showed bronchiectasis.

DISCUSSION: Rhinitis and gastroesophageal reflux disease were the most common comorbidities observed, in addition to bronchiectasis. Therefore, in patients with severe asthma, associated diseases should be investigated as the cause of respiratory symptoms and uncontrolled asthma.
\end{abstract}

KEYWORDS: Severe Asthma; Rhinitis; NSAIDs Intolerance; Gastroesophageal Reflux Disease; Bronchiectasis.

\section{INTRODUCTION}

The prevalence of asthma is increasing in most countries. The global prevalence ranges from 1 to $18 \%$, which makes it a public health problem that has increasingly become of interest to researchers. ${ }^{1}$ Around $10 \%$ of asthma patients have severe asthma, and some of these cases are defined as difficult-to-control asthma.

Clinical Immunology and Allergy Department, Faculdade de Medicina da Universidade de São Paulo - São Paulo/SP, Brazil

Emails: saudesos@saudesos.com.br; marcelovivoloaun@yahoo.com.br Tel: 55113071.3189

Received for publication on April 26, 2009

Accepted for publicaito on May 15, 2009
Difficult-to-control severe asthma, although accounting for no more than $5 \%$ of all asthma cases, is responsible for approximately $50 \%$ of the overall costs related to asthma treatment. It is also associated with greater morbidity and mortality. The risk of requiring treatment in the emergency room and of requiring hospitalization is 15 and 20 times greater, respectively, for such patients than for those with less severe forms of asthma..$^{2-5}$

In individuals with severe asthma, comorbidities are common, with the most prevalent being gastroesophageal reflux disease (GERD), sinusitis, allergic rhinitis and nasal polyposis. All of these can lead to worsening of the asthma symptoms. ${ }^{6}$

Allergic rhinitis and allergic asthma are currently 
recognized as manifestations of a single entity: chronic allergic respiratory disease, also known as "united airway disease" ${ }^{7,8}$ The great majority of patients with asthma have rhinitis, which is itself a risk factor for the development of asthma.

Individuals with asthma often present with GERD, which has been shown to exacerbate asthma through mechanisms involving vagal nerve stimulation (esophagobronchial reflex) or microaspiration of gastric contents into the upper airways. ${ }^{9-11}$

Other diseases that are rare and sometimes difficult to diagnose, including vocal cord dysfunction (VCD) and allergic bronchopulmonary aspergillosis (ABPA), are also associated with worse asthma control.

The features of VCD include episodes of involuntary paradoxical movements caused by vocal cord adduction during inspiration, resulting in airway obstruction. Although VCD can be seen in patients with asthma, it can also occur in an isolated form in individuals without respiratory disease. ${ }^{12,13}$

Aspirin-induced asthma (AIA) is a clinical entity characterized by asthma and intolerance to aspirin or nonsteroidal anti-inflammatory drugs (NSAIDs). ${ }^{14}$ AIA and nasal polyposis are associated with an increase in asthma severity. ${ }^{14,15}$

Asthma and bronchiectasis coexist in many patients, and it has been shown that bronchiectasis can contribute to severe and difficult-to-control asthma with pulmonary complications. ${ }^{16}$

In order to improve the treatment of patients with severe asthma and to control the disease, comorbidities must be taken into consideration, and it is important to treat these conditions simultaneously.

We investigated the occurrence of rhinitis, intolerance to NSAIDs, nasal polyposis, GERD, VCD and bronchiectasis in patients with severe asthma.

\section{MATERIALS AND METHODS}

We conducted a retrospective analysis of data obtained from electronic medical records between January 2006 and June 2008 for patients who met the 2008 Global Initiative for Asthma (GINA) criteria for diagnosis of severe persistent asthma. $^{1}$

The patients were asked about symptoms of rhinitis, GERD and intolerance to NSAIDs. Rhinorrhea, nasal pruritus, sneezing and congestion were all considered to be symptoms consistent with rhinitis. The severity and frequency of the symptoms were defined according to the criteria established in the World Health Organization review entitled Allergic Rhinitis and Its Impact on Asthma (ARIA). ${ }^{7}$
Regurgitation, heartburn and retrosternal discomfort were considered to be suggestive of GERD. Only patients presenting specific complaints of exacerbation resulting from the use of aspirin or NSAIDs were considered to be intolerant to those medications.

A diagnosis of VCD was suspected in patients who reported worsening of symptoms or attacks in situations of emotional stress, were refractory to routine asthma treatment, presented cervical inspiratory wheezing, and had a peripheral oxygen saturation that remained above $95 \%$ even during severe attacks. Suspicion of VCD was also raised for patients in whom spirometry revealed flattening of the inspiratory loop of the flow-volume curve, which is suggestive of extrathoracic obstruction, and in those presenting a difficult-to-control clinical profile with normal or only slightly altered pulmonary function. Thus, VCD was considered when there was a discrepancy between clinical features, laboratory exams and treatment.

The study also included esophagogastroduodenoscopy (EGD), videolaryngoscopy and high-resolution computed tomography (CT) scans of the chest. Findings that could be consistent with GERD varied from mild to severe esophagitis, as seen under direct EGD visualization. Other clinical findings suggestive of GERD were seen under videolaryngoscopy as mild to severe posterior laryngitis. The results of endoscopic examination of the larynx were considered consistent with VCD when there was twothirds closure of the vocal cords with a diamond-shaped opening occurring posteriorly during inspiration. The same examination was used to confirm the presence of nasal polyps. We also evaluated CT scans of the chest in order to identify bronchiectasis.

\section{RESULTS}

We evaluated 245 patients, 194 females and 51 males, all of whom were being treated with inhaled corticosteroids. Six patients $(2.5 \%)$ were also receiving oral corticosteroids in an attempt to control their asthma. The mean patient age was 57.8 years, with a range of 21-85 years. Lung function tests and levels of asthma control are summarized in table 1.

Rhinitis was seen in 224 patients $(91.4 \%)$, and the majority of these patients had persistent and moderate-tosevere rhinitis (Figures 1 and 2).

Intolerance to NSAIDs or nasal polyposis was found in 21 patients $(8.5 \%)$. There were 13 patients with intolerance to NSAIDs who did not have nasal polyps, and there were 3 patients with nasal polyposis who did not report intolerance to NSAIDs (Figure 3).

Symptoms of GERD were reported for 173 (70.6\%) of the patients evaluated, although the diagnosis of GERD was 
Table 1 - Demographic data, baseline characteristics, corticosteroid treatment and lung function (all patients)

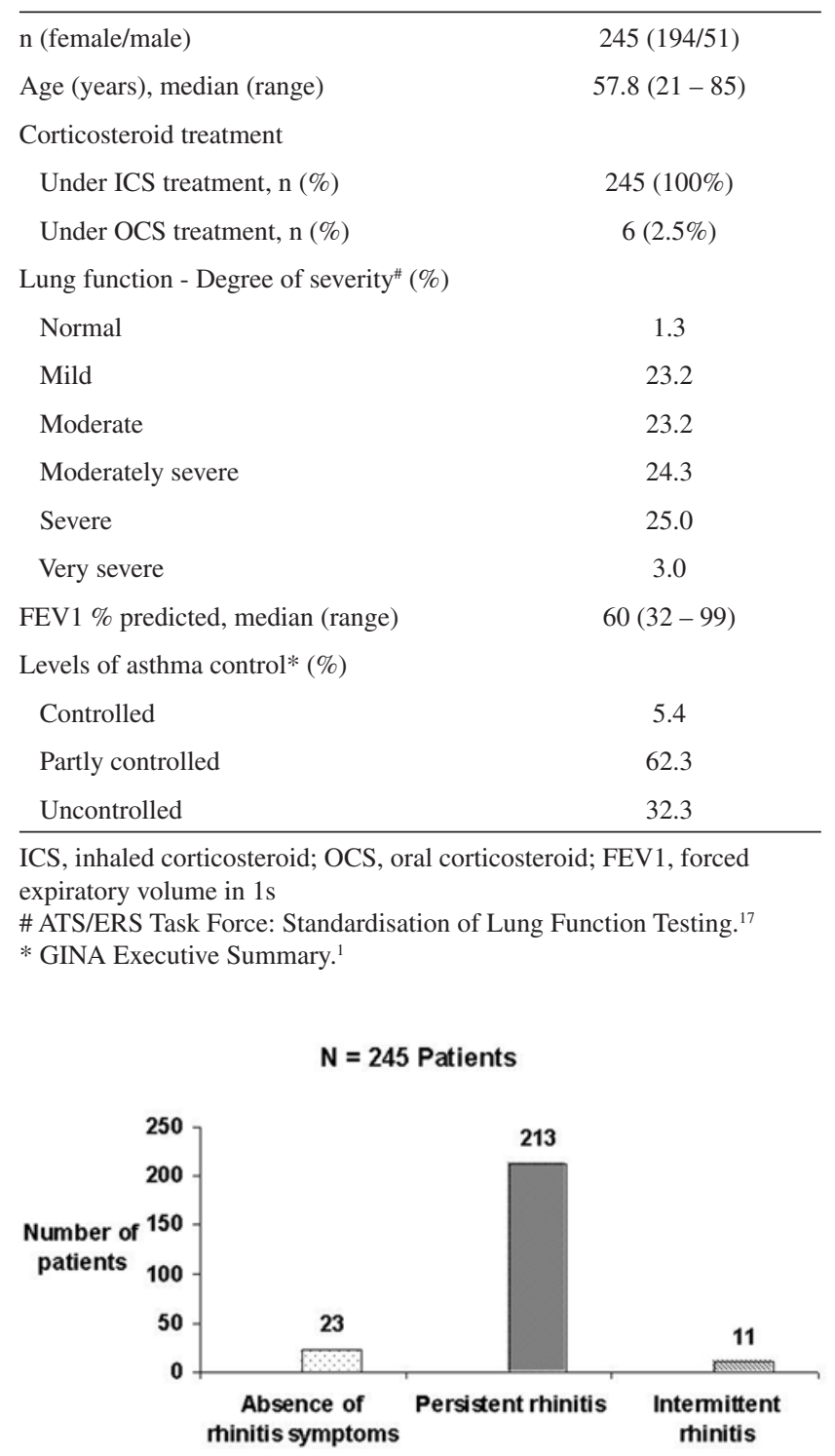

Figure 1 - Frequency of rhinitis symptoms among severe asthma patients (defined according to the criteria established in Allergic Rhinitis and its Impact on Asthma - ARIA ${ }^{7}$ )

\section{$\mathrm{N}=245$ Patients}

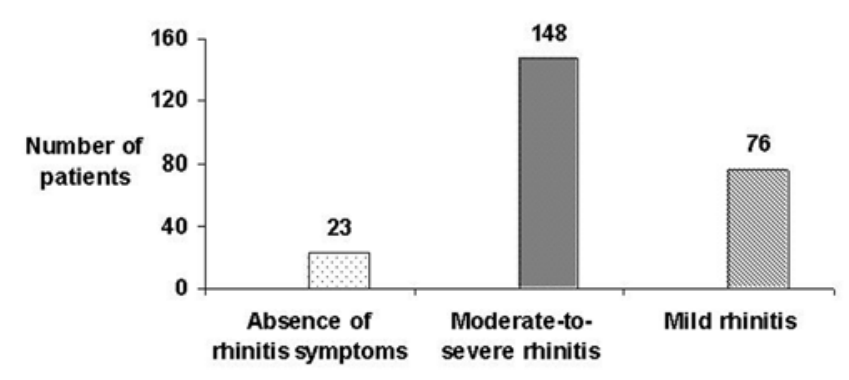

Figure 2 - Severity of rhinitis symptoms among severe asthma patients (defined according to the criteria established in Allergic Rhinitis and its Impact on Asthma - ARIA $)$.

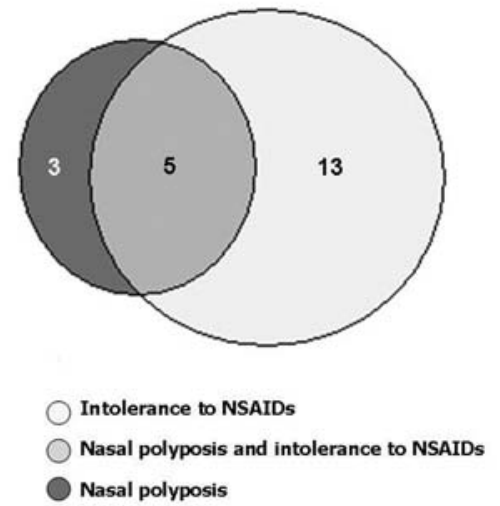

Figure 3 - Frequency of intolerance to nonsteroidal anti-inflammatory drugs (NSAIDs) and nasal polyposis. White color represents intolerance to NSAIDs; Black color represents nasal polyposis

\section{Patients with GERD sym ptom s}

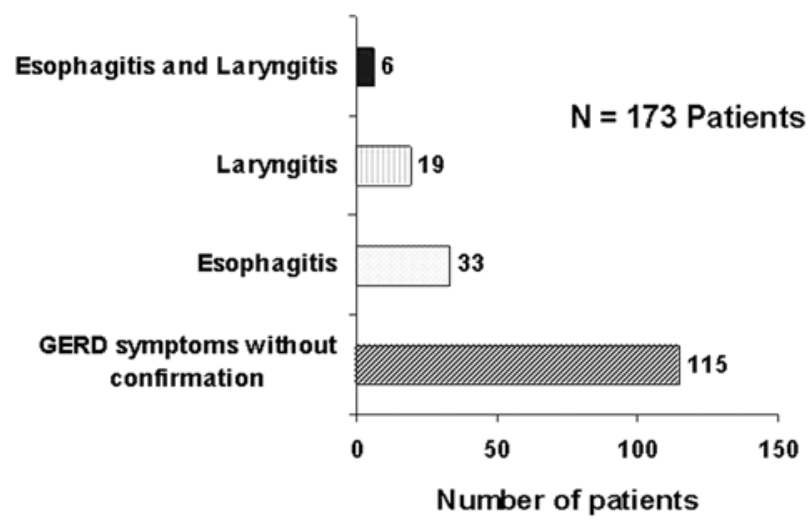

Figure 4 - Patients with gastroesophageal reflux disease (GERD) symptoms and investigation with esophagogastroduodenoscopy (EGD) and videolaryngoscopy. Confirmation of GERD was based on findings of esophagitis or laryngitis

confirmed based on the previously cited criteria in just 58 (33.6\%) (Figure 4).

Among the 245 asthma patients evaluated, VCD was suspected in $16(6.5 \%)$ and confirmed through videolaryngoscopy in $4(1.6 \%)$.

CT scans of the chest were taken for 105 patients, of whom 26 (24.8\%) showed bronchiectasis.

\section{DISCUSSION}

Although only $10 \%$ of asthma cases are classified as severe, such cases are responsible for greater morbidity and mortality. In addition, other factors and comorbidities such as GERD, rhinosinusitis and VCD contribute to poor asthma control, although the exact impact these factors have on the severity of the disease has not been well established. ${ }^{6}$

The prevalence of rhinitis among patients with asthma is 
around 75 to $80 \% .^{7}$ Various studies have demonstrated that among atopic diseases, asthma and rhinitis are the ones most often seen in combination. In addition, allergic rhinitis is considered a major risk factor for the development of asthma, as has been well documented in various countries, including Brazil, in the International Study of Asthma and Allergy in Childhood. ${ }^{18,19}$ The prevalence of rhinitis in the patients with severe asthma evaluated in the present study, however, was higher than that reported in the majority of studies found in the literature. We believe that the high prevalence in our study can be attributed to the fact that our patient population had severe asthma. ${ }^{7}$ Some studies have demonstrated that the presence of severe rhinitis in a patient with asthma is associated with a less favorable outcome. It is also possible that the presence of more than one allergic respiratory disease will lead to an allergy specialist referral. In addition, it has been shown that the treatment of nasal symptoms can be beneficial to the lower respiratory tract, reducing the number of emergency room visits and hospitalizations and limiting bronchial hyperresponsiveness. ${ }^{19,20}$

Although hypersensitivity to NSAIDs and aspirin affects only $0.6-2.5 \%$ of the general population of adults, it occurs in $5-20 \%$ of adults with asthma. ${ }^{21}$ In our sample, only $3.2 \%$ of the patients reported asthma exacerbation after the use of NSAIDs; however, this finding might indicate that many patients are not able to perceive such exacerbation, as has previously been demonstrated. In a study conducted in Europe involving 500 patients diagnosed with aspirinintolerant asthma, 90 (18\%) were unable to perceive worsening symptoms prior to the provocation test. ${ }^{21}$ In the present study, only the clinical profile of NSAID-induced bronchospasm was considered. None of the patients underwent a challenge test.

Asthma and GERD frequently coexist. ${ }^{22}$ Concomitance between symptoms of dyspnea and reflux is quite common, and large-scale studies have shown that the degree of reflux can be as much as $60 \%$ greater in those with asthma as compared to individuals without asthma. ${ }^{23}$ In a study conducted in the United Kingdom, the prevalence of GERD symptoms among patients with difficult-to-control asthma was found to be $75 \%$, which is comparable to the findings in our sample. ${ }^{24}$ In the same study, however, 24-h pH-metry revealed the true prevalence to be only $55 \%$. In the present study, the patients were submitted to EGD and videolaryngoscopy, through which 58 patients (23.6\%) were diagnosed with concomitant asthma and GERD. Not all of our patients, however, underwent these tests.

Despite the fact that VCD has been increasingly studied, its prevalence has yet to be well defined. In Brazil, the reported prevalence of VCD is around $17.5 \%$ among patients with severe asthma. ${ }^{12}$ In our study, the patient charts indicated that VCD was suspected in only $6.5 \%$ of cases. We believe that VCD is under-diagnosed, however, since the diagnosis was confirmed in more than 16 patients at our outpatient clinic. ${ }^{25,26}$

It is common to see abnormal CT scan results in those with asthma, as previously reported by several authors. In addition to abnormalities such as hyperinflation, mucoid impaction, acinar pattern, lobar collapse and bronchial wall thickening, which are expected in patients with asthma, other less common findings such as bronchiectasis are increasing in frequency. The reported incidence of bronchiectasis among asthma patients is between $37 \%$ and $65 \%$. The use of $\mathrm{CT}$ for the diagnosis of bronchiectasis has been validated in various studies in which the patients were submitted to CT and bronchogram. ${ }^{27}$

Autopsy studies have shown that $15-20 \%$ of patients who died from exacerbation of asthma had bronchiectasis, most often in the upper lobes. One hypothesis to explain the prevalence of bronchial dilation in asthma patients is destruction of the bronchi by an inflammatory process or recurrent infection. In our study, 24.8\% of 105 patients who underwent CT showed bronchiectasis. Some of these patients could have also had ABPA, which is difficult to diagnose. It has been reported that the majority of patients do not meet all of the diagnostic criteria simultaneously, and many such patients are receiving corticosteroid therapy, which can mask the symptoms. ${ }^{27}$

\section{CONCLUSIONS}

Rhinitis and GERD were the most common comorbidities observed, in addition to bronchiectasis. Therefore, in patients with severe asthma, associated diseases should be investigated as the cause of respiratory symptoms and uncontrolled asthma.

\section{REFERENCES}

1. Bateman ED, Hurd SS, Barnes PJ, Drazeni JM, FitzGerald M, Gibson $\mathrm{P}$, et al. Global strategy for asthma management and prevention: GINA executive summary. Eur Respir J. 2008;31:143-78.

2. Barnes PJ, Woolcock AJ. Difficult asthma. Eur Respir J. 1998;12:120918.
3. Serra-Batlles J, Plaza V, Morejón E, Comella A, Brugues J. Costs of asthma according to the degree of severity. Eur Respir J. 1998;12:1322-6.

4. American Thoracic Society. Proceedings of the ATS Workshop on Refractory Asthma. Current understanding, recommendations, and unanswered questions. Am J Respir Crit Care Med. 2000;162:2341-51. 
5. Antonicelli L, Bucca C, Neri M, De Benedetto F, Sabbatani P, Bonifazi F, et al. Asthma severity and medical resource utilization. Eur Respir J. 2004;23:723-9.

6. Stirling RG \& Chung KF. Severe asthma: definition and mechanisms. Allergy. 2001;56:825-40.

7. Bousquet J, Van Cauwenberge P, Khaltaev N; ARIA Workshop Group; World Health Organization. Allergic rhinitis and its impact on asthma. J Allergy Clin Immunol. 2001;108:S147-333.

8. Togias A. Rhinitis and asthma: Evidence for respiratory system integration. J Allergy Clin Immunol. 2003;111:1171-83.

9. Harding SM, Richter JE, Guzzo MR, Schan CA, Alexander RW, Bradley LA. Asthma and gastroesophageal reflux: acid suppressive therapy improves asthma outcome. Am J Med. 1996;100:395-405.

10. Sharma B, Sharma M, Daga MK, Sachdev GK, Bondi E. Effect of omeprazole and domperidone on adults asthmatics with gastroesophageal reflux. World J Gastroenterol. 2007;13:1706-10.

11. Littner MR, Leung FW, Ballard ED 2nd, Huang B, Samra NK; Lansoprazole Asthma Study Group. Effects of 24 weeks of lansoprazole therapy on asthma symptoms, exacerbations, quality of life, and pulmonary function in adult asthmatic patients with acid reflux symptoms. Chest. 2005; 128:1128-35.

12. Giavina-Bianchi P, Pinto LHE, Sayed S, Cukier A, Kalil J. Development of a specific questionnaire for the suspicion of DPV. In: AAAAI Annual Meeting, 2007, San Diego. J Allergy Clin Immunol. 2007a;119:S16.

13. Awad OG, Fasano MB, Lee JH, Graham SM. Asthma outcomes after endoscopic sinus surgery in aspirin-tolerant versus aspirin-induced asthmatic patients. Am J Rhinol. 2008;22:197-203.

14. Ceylan E, Gencer M, San I. Nasal polyposis and the severity of asthma. Respirology. 2007;12:272-6.

15. Oguzolgen IK, Kervan F, Ozis T, Turktas H. The impact of bronchiectasis in clinical presentation of asthma. South Med J. 2007;100:468-71.

16. Pastorino AC, Rimazza RD, Leone C, Castro AP, Solé D, Jacob CM. Risk factors for asthma in adolescents in a large urban region of Brazil. J Asthma. 2006;43:695-700.

17. Pellegrino R, Viegi G, Brusasco V, Crapo RO, Burgos F, Casaburi R et al. Interpretative strategies for lung function tests - Series "ATS/ERS Task Force: Standardisation of Lung Function. Eur Respir J. 2005;26:948-68.
18. Lima RG, Pastorino AC, Casagrande RR, Sole D, Leone C, Jacog CM. Prevalence of asthma, rhinitis and eczema in 6-7 years old students from the western districts of Sao Paulo City, using the standardized questionnaire of the "International Study of Asthma and Allergies in Childhood" (ISAAC)-phase IIIB. Clinics. 2007;62:225-34.

19. Stelmach R, Patrocínio T, Nunes M, Ribeiro M, Cukier A. Effect of treating allergic rhinitis with corticosteroids in patient with mild-tomoderate persistent asthma. Chest. 2005;128:3140-7.

20. Agondi RC, Machado ML, Kalil J, Giavina-Bianchi P. Intranasal corticosteroid administration reduces nonspecific bronchial hyperresponsiveness and improves asthma symptoms. J Asthma. 2008;45:754-7.

21. Pfaar O \& Klimek L. Aspirin desensitization in aspirin intolerance: update on current standards and recent improvements. Curr Opin Allergy Clin Immunol. 2006;6:161-6.

22. Gibson PG, Henry RL, Coughlan JL. Gastro-oesophageal reflux treatment for asthma in adults and children. Cochrane Database Syst Rev. 2003;(2):CD001496.

23. Nordenstedt H, Nilsson M, Johansson S, Wallander MA, Johnsen R, Hveem K, et al. The relation between gastroesophageal reflux and respiratory symptoms in a population-based study: the Nord-Trondelag health survey. Chest. 2006;129:1051-6.

24. Leggett JJ, Johnston BT, Mills M, Gamble J, Heaney LG. Prevalence of gastroesophageal reflux in difficult asthma: relationship to asthma outcome. Chest. 2005;127:1227-31.

25. Newman KB, Mason III UG, Schmaling KB. Clinical features of vocal cord dysfunction. Am J Respir Crit Care Med. 1995;152:1382-6.

26. Ibrahim WH, Gheriani HA, Almohamed AA, Raza T. Paradoxical vocal cord motion disorder: past, present and future. Postgrad Med J. 2007;83:164-72.

27. Cukier A, Stelmach R, Kavakama JI, Terra Filho M, Vargas F. Persistent asthma in adults: comparison of high resolution computed tomography of the lungs after one year of follow-up. Rev Hosp Clín Fac Med S Paulo. 2001;56:63-8 